\title{
Topical Nanoemulgel: A Novel Pathway for Investigating Alopecia
}

\section{Gurjot Kaur $^{1 *}$, Bedi PMS ${ }^{1}$ and Jasjeet K Narang ${ }^{2}$}

${ }^{1}$ Department of Pharmaceutical sciences, Guru Nanak Dev University, Amritsar-143005, India

${ }^{2}$ Department of Pharmaceutics, Khalsa College of Pharmacy, Amritsar-143001, India

\begin{abstract}
Alopecia areata (hair loss) is an auatoimmune disease occurs in both sexes and is characterized by partial, complete and total body hair loss. The severity of the condition and the patient's age are the tailored factors responsible for the hair loss. The FDA approved Minoxidil as a topical medication with proven efficacy for treating different types of alopecia's. This review will discuss the effect of topical nanoemulgel over other formulations for the treatment of alopecia areata. The nanoemulgel will shows better solubility and permeability of the active components at the site of application via opening of hair follicles or other routes, as compared to other formulations.
\end{abstract}

Keywords: Alopecia areata; Minoxidil; Nanoemulsion; Topical nanoemulgel; Higher permeability

\section{Introduction}

Alopecia is the type of hair loss characterized as partial, complete and total loss of body hair [1]. Alopecia areata and androgenic alopecia (AGA) (male pattern baldness) are the other types which affects the scalp hair loss [2].

Recently, a genome-wide association study demonstrated a genetic predisposition to alopecia areata. The factors like viral infections, trauma, or psychosocial stress, have also been suspected to possibly contribute to the development of the disease [3].

The treatments for the alopecia areata include topical, locally injected, or systemic steroids; topical immunotherapy; topical minoxidil; topical irritants such as anthralin; and systemic immunosuppressants such as cyclosporine or methotrexate. Success rates vary depending on the extent and duration of disease [3]. The FDA had approved only minoxidil and finasteride for the treatment of AGA. Minoxidil, the FDA approved topical medication with proven efficacy is the best option for investigating the different factors responsible for alopecia [4].

\section{Minoxidil acting pathway}

The Minoxidil exert its action by transforming into active metabolite (minoxildilsulfate) with the help of sulphotranspherase enzyme mainly present in the scalp [5]. The hair cycle is the most preferred pathway for minoxidil to exert its action. It also increases the hair diameter and lengthen the anagen phase by proliferative and anti-apoptotic effects on dermal papilla cells of the hair follicles [2]. It also increases the blood supply to the scalp allowing more oxygen, blood, and nutrients to the follicle. The oral use of minoxidil results in several side effects like weight gain, severe water retention, etc. In order to avoid these side effects, the topical formulations of minoxidil are going to be the best treatment for alopecia by showing its better efficacy and prolong drug action [6].

\section{Novel topical drug delivery system}

While there are variety of drug carriers used in topical therapeutics such as niosomes, liposomes, NLCs, SLNs, microemulsions, topical gels, but they remains confined mostly on the skin surface leads to improper drug efficiency [7]. Therefore, Nanoemulgels (Figure 1) will prove itself as a best topical preparation because of its enhanced permeation into skin and hair shaft with sustained effects at the site of application.

\section{Advantages of nanoemulgels}

The nanoemulgel offers various advantages over other investigated topical formulations [8] which are [9]:

- Avoid first pass metabolism.

- Easy acceptable for patient

- Suitably for self-medication

- Provide local drug delivery.

- Easy termination of medication.

- Easily acceptable for skin environment.

- Proven efficacy for controlled and sustained drug delivery system.

\section{Formulation of topical nanoemulgel}

Topical nanoemulgel is formulated by adding gelling agent to the optimized nanoemulsion formulation and therefore exhibit characteristics both of nanoemulsions and gels.

\section{Nanoemulsions}

Nanoemulsion system is an ideal drug delivery for most of the drugs with objective of maximizing efficacy while minimizing toxicity. In the advancement of research, researchers have excogitate the simple drug delivery to eminently refined novel dosage forms [10].

Nanoemulsion system comprises the mixture of nanoranges of two immissible liquids (water and oil) to form a homogeneous system by adding suitable surfactant/cosurfactants with appropriate HLB value. This thermodynamically stable system ranges from 10-100 nm [11]. Figure 2 explain the different compartments of a stabilized nanoemulsion.

*Corresponding author: Gurjot Kaur, Department of Pharmaceutical Sciences, Guru Nanak Dev University, Amritsar-143005, Punjab, India, Tel: 917837552182 E-mail: gurjotk.06@gmail.com

Received: November 03, 2017; Accepted: November 29, 2017; Published: December 05, 2017

Citation: Kaur G, Bedi PMS, Narang JK (2017) Topical Nanoemulgel: A Nove Pathway for Investigating Alopecia. J Nanomed Nanotechnol 8: 472. doi: 10.4172/2157-7439.1000472

Copyright: ( 2017 Kaur G, et al. This is an open-access article distributed unde the terms of the Creative Commons Attribution License, which permits unrestricted use, distribution, and reproduction in any medium, provided the original author and source are credited. 
Citation: Kaur G, Bedi PMS, Narang JK (2017) Topical Nanoemulgel: A Novel Pathway for Investigating Alopecia. J Nanomed Nanotechnol 8: 472. doi: 10.4172/2157-7439.1000472

\section{Large, conventional \\ topical preparation \\ Topical Nanoemulgel}

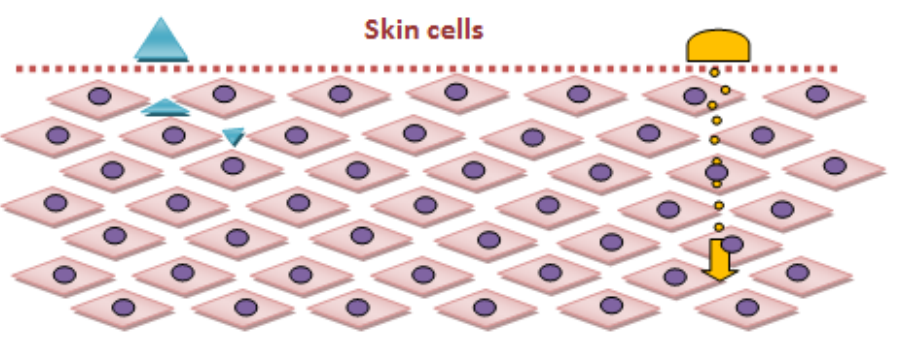

Shallow penetration, does not reach fibroblast

\section{Carry active moiety into deep}

inside the skin

There is $70 \mathrm{~nm}$ space between each skin cells. $\mathcal{N}$ ormal emulsified products penetrate into skin slowly. The topical Nanoemulgel rapidly penetrate and defiver active substances deeper and quicker. In addition, with the gel based formulation of nanoemulgel, it exhibit upgraded properties of non greasy. effortlessly spreadable, easily be removed and longer shelf life.

Figure 1: Comparison of topical nanoemulgel with other topical preparations.

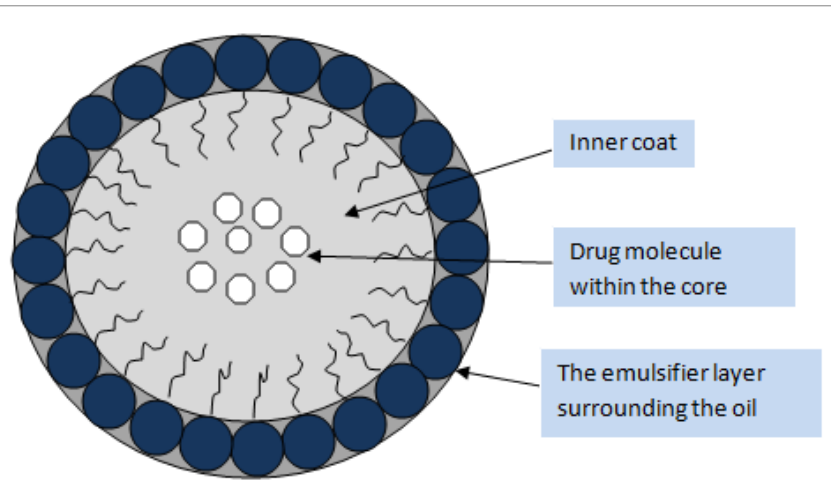

Figure 2: Diagram of Stabilized Nanoemulsion.

These stabilised nanoemulsions are excogitate from generally regarded as safe (GRAS) surfactants. These stabilized system are able to dissolve drugs of low solubility and enert them from hydrolytic and enzymatic degradation. These novel system helps in increasing the drug loading, enhancing the drug solubility, bioavailability, etc. [10]. Nanoemulsions preferred topical route as compare to oral administrative due to bitter taste [10,12]. With the help of suitable gelling agents or polymers, these nanoemulsions will show better results when applied topically.

\section{Components of nanoemulsion}

The main components of nanoemulsion are as follows:

Oil: The selection of oil phase is the most important parameter in order to obtain a stabilized nanoemulsion, so that maximum amount of drug could solubilise in it [13]. Usually, the oil which has maximum solubilising potential for selected drug candidate is selected as an oily phase for the formulation of nanoemulsions. This helps to achieve maximum drug loading in the nanoemulsions [14]. Mixture of oils can also be used to solubilsed the maximum amount of drug [15]. The different oils used for the nanoemulsion formulation are enlisted in Table 1.

\begin{tabular}{|c|c|}
\hline Oils & Botanical Names \\
\hline Arachis oil (Peanut oil) & Arachis hypogaea \\
\hline Brahmi oil & Bacopa monnieri \\
\hline Clove oil & Syzygium aromaticum \\
\hline Linseed oil (Flax seed oil) & Linum usitatissimum \\
\hline Eucalpytus oil & Eucalyptus globules \\
\hline Jojoba oil & Buxus chinensis \\
\hline Peppermint oil & Mentha piperita \\
\hline Neem oil & Azadirachta oil \\
\hline Tea tree oil & Melaleuca alternifolia \\
\hline
\end{tabular}

Table 1: List of oils used in nanoemulsion.

\begin{tabular}{|l|l|}
\hline Surfactants & Chemical Names \\
\hline Kolliphor RH 40 & Macrogolglycerol hydroxystearate \\
\hline Ursolic acid & $3 \beta$-Hydroxy-12-ursen-28-ic acid \\
\hline Labrafil M 1944 CS & Oleoyl polyoxylglycerides \\
\hline Lauroglycol FCC & Propylene glycol monolaurate \\
\hline PEG MW>4000 & Carbowax, polyglycol \\
\hline Plurol Oleique CC 497 & Polyglyceryl-3 dioleate \\
\hline Poloxamer 188 & $\begin{array}{l}\text { Poly(ethyleneglycol)-block-poly(propylene glycol)- } \\
\text { block-poly(ethylene glycol) }\end{array}$ \\
\hline
\end{tabular}

Table 2: List of surfactants used in nanoemulsion.

Surfactant: Surfactants are the important component used for stabilizing the nanoemulsion system. The anionic, cationic, and nonionic types of surfactants are used in this system. Due to their different chemical nature, proper selection of surfactants (Table 2) becomes a crucial factor to obtain a stabilized delivery system. For the formation of a stable nanoemulsion, surfactants having proper HLB value are required $[13,16]$.

Cosurfactant: Cosurfactant plays an important role in reducing the polarity of surfactant to obtain a stabilized nanoemulsion. There are varieties of cosurfactants (Table 3), which acts on surfactants interface, such as short- to medium-chain length alcohols (C3-C8). These are also helpful in increasing the penetrability of oil to get a stabilized formulation [15]. 


\begin{tabular}{|c|c|c|}
\hline Co-surfactants & Molecular formula & Molecular weight \\
\hline Transcutol $\mathrm{P}$ & $\mathrm{C}_{6} \mathrm{H}_{14} \mathrm{O}_{3}$ & $134.175 \mathrm{~g} / \mathrm{mol}$ \\
\hline Glycerol & $\mathrm{C}_{3} \mathrm{H}_{8} \mathrm{O}_{3}$ & $92.09382 \mathrm{~g} / \mathrm{mol}$ \\
\hline Propylene glycol & $\mathrm{C}_{3} \mathrm{H}_{8} \mathrm{O}_{2}$ & $76.095 \mathrm{~g} / \mathrm{mol}$ \\
\hline Ethanol & $\mathrm{C}_{2} \mathrm{H}_{6} \mathrm{O}$ & $46.068 \mathrm{~g} / \mathrm{mol}$ \\
\hline Propanol & $\mathrm{C}_{3} \mathrm{H}_{8} \mathrm{O}$ & $60.095 \mathrm{~g} / \mathrm{mol}$ \\
\hline
\end{tabular}

Table 3: List of co-surfactants used in nanoemulsion.

\begin{tabular}{|l|c|c|}
\hline Name of gelling agent & Molecular formula & Molecular weight (g/mol) \\
\hline Poloxamer & $\mathrm{C}_{5} \mathrm{H}_{10} \mathrm{O}_{2}$ & 102.133 \\
\hline Polyacrylamide & $\mathrm{C}_{3} \mathrm{H}_{5} \mathrm{NO}$ & 71.077 \\
\hline Hydrin rubber, neoprene & $\mathrm{C}_{4} \mathrm{H}_{5} \mathrm{Cl}$ & 88.534 \\
\hline HPMC 55 & $\mathrm{C}_{3} \mathrm{H}_{7} \mathrm{O}$ & 59.087 \\
\hline Carbomer 934 & $\mathrm{C}_{3} \mathrm{H}_{4} \mathrm{O}_{2}$ & $3,000,000$ \\
\hline
\end{tabular}

Table 4: Examples of gelling agents.

Aqueous phase: The nature of aqueous phase mainly influenced the droplet size and the stability of nanoemulsion. The physiological milieu has diverse $\mathrm{pH}$ ranges varying from $\mathrm{pH} 1.2$ ( $\mathrm{pH}$ in stomach) to 7.4 and greater ( $\mathrm{pH}$ of blood and intestine). In addition, the presence of various ions in the physiological milieu can also have considerable effect on the properties of nanoemulsions [15]

\section{Fabrication methods for preparing stabilized nanoemulsions}

In order to get clear and stabilized nanoemulsion formulations, proper fabrication techniques should be adopted [17]. The techniques are mandatory in reducing the droplet size to nanoscale [18].

Homogenization using high pressure: For the preparation of stabilized nanoemulsion with particle size $1 \mathrm{~nm}$, the high-pressure homogenizer piston is used by applying several forces, such as cavitation, etc. This process will continue until a desired nanosize formulation is obtained [13].

Microfluidization: Microfluidization of the prepared formulation is done by the use of device known as microfluidizer. The use of high pressure forces the product into microchannels in order to get a submicron range particle. The process is repeated until a stabilized nanoemulsion is obtained [19].

Ultrasonication: In case of ultrsonication technique, ultrasonic vibrations are used to obtain stabilized nanoemulsion with reduced particle size. In this, cavitation is the preferable mechanism for obtaining desired nanosized formulation [17].

\section{Phase inversion method}

A stabilized nanoemulsion is obtained by using phase inversion method which endorses chemical energy for phase transition with the help of emulsification process under a constant temperature [18].

\section{Gelling agents (hydrogels)}

The unique physical properties of hydrogels have reflected particular interest in drug delivery applications. These are the semisolid system with three-dimensional, cross-linked network of organic and inorganic molecules and imbibition by liquid due to high porosity [20].

Due to rapid researches in nanotechnology, there is sudden change which welcomes the new nanogel systems. Table 4 has proven their potential to deliver drugs in controlled, sustained and targetable manner. They have high drug loading capacity, biocompatibility, and biodegradability which are the key points to design an effective drug delivery system [21].

\section{Preparation of nanoemulgel formulation}

Nanoemulsion base gels are prepared by incorporation of $1 \mathrm{~g}$ of gelling agent in a sufficient quantity of distilled water. This gelling agent solution is place under dark conditions for 25 hours until complete swelling system obtained. Then the drug loaded nanoemulsion is slowly added to the viscous solution of gelling agent under magnetic stirring. The $\mathrm{pH}$ is stabilized by the addition of $0.1 \mathrm{ml}$ of triethanolamine (TEA). The formed nanoemulgels are kept for $24 \mathrm{~h}$ to obtain a homogeneous dispersion of gel [22].

\section{Characterizaion of Nanoemulgel Formulations}

The nanoemulgel formulations are characterized by the following techniques

\section{Physicochemical parameters}

The prepared nanoemulgel formulations are inspected visually for their color, homogeneity, consistency and phase separation [23].

\section{pH Determination}

The $\mathrm{pH}$ of the prepared formulations is determined by $\mathrm{pH}$ using meter. In this, the formulations are place in $250 \mathrm{ml}$ beaker and immersing the $\mathrm{pH}$ meter into the formulation and record the readings. Same process is repeated for three times with same formulation [24].

\section{Rheological investigation}

The viscosity of the different nanoemulgel formulations is determined at $25^{\circ} \mathrm{C}$ using a cone and plate viscometer or Brookfield viscometer with appropriate spindle\# and connected to a thermostatically controlled circulating water bath [15].

\section{Globule size distribution in nanoemulgel}

Globule size and distribution are determined by Malvern zetasizer. A $1 \mathrm{~g}$ sample is dissolved in purified water and agitated to get homogeneous dispersion. Sample is injected into photocell of zetasizer to obtain mean globule diameter and distribution [25].

\section{Spreading coefficient}

Spreadability is determined by apparatus which consists of a wooden block, which is provided by a pulley at one end. The spreadability is measured on the basis of 'Slip' and 'Drag' characteristics of nanoemulgels. A ground glass slide is fixed on this block. An excess of nanoemulgel (about $2 \mathrm{~g}$ ) under study is placed on this ground slide. The nanoemulgel is then sandwiched between this slide and another glass slide. A $1 \mathrm{Kg}$ weight is placed on the top of the two slides for 5 minutes to expel air and to provide a uniform film of the nanoemulgel between the slides. By putting weight of $80 \mathrm{~g}$, the time (in seconds) required by the top slide to cover a distance of $7.5 \mathrm{~cm}$ with the help of string attached to the hook is noted [24].

A shorter interval indicates better spreadability, which is calculated by the formulae:

\section{$\mathrm{S}=\mathrm{M} \cdot \mathrm{L} / \mathrm{T}$}

Where, $S=$ Spreadability,

M=Weight tied to upper slide,

$\mathrm{L}=$ Length of glass slides

$\mathrm{T}=$ Time taken to separate the slides completely from each other. 
Citation: Kaur G, Bedi PMS, Narang JK (2017) Topical Nanoemulgel: A Novel Pathway for Investigating Alopecia. J Nanomed Nanotechnol 8: 472. doi: 10.4172/2157-7439.1000472

Page 4 of 5

\section{Extrudability study (tube test)}

This test is used to measure the force required to extrude the material from tube. The evaluation of extrudability is based upon the quantity of nanoemulgel extruded from lacquered aluminium collapsible tube on application of weight in grams required to extrude at least $0.5 \mathrm{~cm}$ ribbon of nanoemulgel in 10 seconds. The better extrudability is depend upon the quantity extruded [25]. The extrudability is than calculated by using the following formula

Extrudability=Applied weight to extrude nanoemulgel from tube (in g)/Area (in $\mathrm{cm}^{2}$ ).

\section{Drug content determination}

The drug content is determined by mixing appropriate amount of nanoemulgel formulation in suitable solvent. Then the solution is passed through whatman filter paper and filtrate is analyze for drug content by uv spectrophotometrically using the same standard plot by putting the value of absorbance as given by More et al. [24].

\section{Skin irritation test (patch test)}

The preparation is applied on the properly shaven skin of rat and undesirable changes in colour, change in skin morphology should be checked up to 24 hours. If no irritation occurs the test is passed [26].

\section{In vitro release study}

The Franz diffusion cell (with effective diffusion area $3.14 \mathrm{~cm}^{2}$ and $15.5 \mathrm{ml}$ cell volume) is used for the drug release studies. Nanoemulgel is applied onto the surface of dialysis membrane evenly and clamped between the donor and the receptor chamber of diffusion cell. The receptor chamber is filled with freshly prepared phosphate buffer saline pH 5.5 solutions to solubilise the drug. The receptor chamber is stirred by magnetic stirrer. The samples $(1.0 \mathrm{ml}$ aliquots) are collected at suitable time interval. Samples are analyzed for drug content by UV visible after appropriate dilutions. The cumulative amount of drug released across the dialysis membrane is determined [27].

\section{Drug release kinetic study}

To analyze the mechanism of drug release from the topical nanoemulgel, the release data [28] are fitted to following equations:

Zero-order equation:

$\mathrm{Q}=\mathrm{K}_{0} \mathrm{t}$

Where $\mathrm{Q}$ is the amount of drug released at time $t$, and $\mathrm{K}_{0}$ is the zero-order release rate.

First-order equation:

$$
\text { In }(100-\mathrm{Q})=\text { In } 100-\mathrm{K}_{1} \mathrm{t}
$$

Where $\mathrm{Q}$ is the percentage of drug release at time $\mathrm{t}$, and $\mathrm{K}_{1}$ is the first-order release rate constant.

Higuchi's equation:

$$
\mathrm{Q}=\mathrm{K}_{2} \sqrt{\mathrm{t}}_{\mathrm{t}}
$$

Where $\mathrm{Q}$ is the percentage of drug release at time $t$, and $\mathrm{K}_{2}$ is the diffusion rate constant

\section{Stability studies}

The prepared nanoemulgels are packed in aluminium collapsible tubes $(5 \mathrm{~g})$ and subjected to stability studies at $5^{\circ} \mathrm{C}, 25^{\circ} \mathrm{C} / 60 \% \mathrm{RH}$, $30^{\circ} \mathrm{C} / 65 \% \mathrm{RH}$, and $40^{\circ} \mathrm{C} / 75 \% \mathrm{RH}$ for a period of 3 months. Samples are withdrawn at 15-day time intervals and evaluated for physical appearance, $\mathrm{pH}$, rheological properties, drug content, and drug release profile [23].

\section{Accelerated stability studies of gellified nanoemulsion}

Stability studies are performed according to $\mathrm{ICH}$ guidelines. The formulations are stored in hot air oven at $37 \pm 2^{\circ}, 45 \pm 2^{\circ}$ and $60 \pm 2^{\circ}$ for a period of 3 months. The samples are analyzed for drug content every two weeks by UV-Visible spectrophotometer. Stability study is carried out by measuring the change in $\mathrm{pH}$ of formulation at regular interval of time [29].

\section{Conclusion}

There are a number of products suit to treat hair loss contributing to the big market worldwide. There are many patents for potential useful or doubtful anti-hair loss agents. Some agents advertised as effective "anti-hair loss" remedies, but are not supported by convincing studies. These unsupported results from inefficient drug action and insufficient assessment of the basic pathology of hair loss. This is the reason why "great expectations" turn into plenty of disappointments. Research has revealed that the nanomaterials enhance the benefits of active ingredients when engineered into hair care. For the development of tailored products and new technologies capable of achieving improved hair care, enhanced knowledge of the composition of the hair fiber and an understanding of follicular targeting pathways should be there. Although there are already developed nanoformulations existing in market, nanoemulgels are going to be the promising products for better hair care and an effective and safe topical delivery system for the treatment of alopecia areata.

\section{References}

1. Parhi R, Terapalli BR, Teja BB (2014) Formulation and in vivo evaluation of minoxidil topical gel. Turk J Pharm Sci 11: 153-162.

2. Usmania, Bilandi A, Kataria MK (2017) Minoxidil emulgel for androgenic alopecia: A literature review including patents. Int J Pharm Drug Anal 5: 49-58.

3. Fricke ACV, Miteva M (2015) Epidemiology and burden of alopecia areata: a systematic review. Clin Cosmet Investig Dermatol 8: 397-403.

4. Messenger AG, Rundergren J (2004) Minoxidil: Mechanisms of action on hair growth. Br J dermatol 150: 186-194.

5. Palanisamy T (2014) Minoxidil to Treat Androgenetic Alopecia in Men and Women: What is It \& How does It Work? AJMMS 4: 262-265.

6. Rogers NE, Avram MR (2008) Medical treatment for male and female pattern hair loss. J Am Acad Dermatol: 547-52.

7. Rani D, Singh C, Kumar A, Sharma VK (2016) Formulation Development and In-vitro Evaluation of Minoxidil Bearing Glycerosomes. AJBR 4: 27-37.

8. Hyma P, Jahan N, Babu K, Sreelekha G, Raheemunissa (2014) Emulgel: A review. IJPA 3: 1-11.

9. Chellapa P, Mohamed AT, Keleb El, Elmahgoubi A, Eid AM, et al. (2015) Nanoemulsion and Nanoemulgel as a Topical Formulation. IOSR Journal of Pharmacy 5: 43-47.

10. Chime SA, Kenechukwu FC, Attama AA (2014) Nanoemulsions-advances in formulation, characterization and applications in drug delivery. Application of Nanotechnology in Drug Delivery.

11. Bhosale RR, Osmani RA, Ghodake PP, Shaikh SM, Chavan SR (2014) Nanoemulsion: A review on novel profusion in advanced drug delivery. Indian J Pharm Biol Res 2: 122-127.

12. Sutradhar KB, Amin ML (2013) Nanoemulsions: increasing possibilities in drug delivery. Eur J Nanomed 5: 97-110.

13. Mangale MR, Pathak SS, Mene HR, More BA (2015) Nanoemulsion: as pharmaceutical overview. IJPSRR 33: 244-252. 
Citation: Kaur G, Bedi PMS, Narang JK (2017) Topical Nanoemulgel: A Novel Pathway for Investigating Alopecia. J Nanomed Nanotechnol 8: 472. doi: $10.4172 / 2157-7439.1000472$

Page 5 of 5

14. Date AA, Nagarsenker MS (2008) Parenteral microemulsion: An overview. Int J Pharm 355: 19-30.

15. Debnath S, Satayanarayan, Kumar GV (2011) Nanoemulsion-A method to improve the solubility of lipophilic drugs. Pharmanest - An International Journal of Advances in Pharmaceutical Sciences 2: 72-83.

16. Shah $P$, Bhalodia D, Shelat $P(2010)$ Nanoemulsion: a pharmaceutical review. Sys Rev Pharm 1: 24-32.

17. Mishra RK, Soni GC, Mishra RP (2014) Nanoemulsion: A review article. World J Pharm Pharm Sci 3: 258-274.

18. Saudagar RB, Vaishnav S (2016) Pharmaceutical nanoemulsion as a rational carrier for drug delivery - An overview. Research Journal of Pharmacy and Technology.

19. Chouksey RK, Pandey HK, Maithil A, Jain AK (2011) Nanoemulsion: A review. Inventi Journals 2: 1-23.

20. Hoare TR, Kohane DS (2008) Hydrogels in drug delivery: Progress and challenges. Polymer 49: 1993-2007.

21. Sultana SS, Parveen P, Rekha MS, Deepthi K, Sowjanya C, et al. (2014) Emulgel - A Novel Surrogate Appraoch For Transdermal Drug Delivery System. Indo Am J Pharm Res 4: 5250-5265.

22. Modi JD, Patel JK (2011) Evaluate in vivo and in vitro model on naoemulsion based gel formualtion of aceclofenac. IJPPR 2: 230-234.
23. Dev A, Chodankar R, Shelke O (2015) Emulgels: A novel topical drug delivery system. Pharmaceutical and Biological Evaluations 2: 64-75.

24. More A, Ambekar AW (2016) Development and Characterization of Nanoemulsion Gel for Topical Drug Delivery of Nabumetone. IJPPR 7: 126-157.

25. Lakshmana PS, Sharvanan SP, Aravindan S, Bhuvaneswari A, Manikandan V (2017) Nanoemulgel for transdermal delivery of cyclobenzaprine hydrochloride: design, characterization and in vitro studies. Novel Appro Drug Des Dev 1: 1-6.

26. Soujanya C, Satya BL, Reddy ML, Manogna K, Prakash PR, et al. (2014) Formulation and in vitro and in vivo evaluation of transdermal patches of lornoxicam using natural permeation enhancers. Int J Pharm Pharm Sci 6: 282-286.

27. Bhagat KA, Bhura MRG, Shah SK (2015) Formulation and evaluation of topical nano emulgel of adapalene. World J Pharm Sci 3: 1013-1024.

28. Srivastava M, Kohli K, Ali M (2014) Formulation development of novel in situ nanoemulgel of ketoprofen for the treatment of periodontitis. Drug Delivery 23 : $1-13$.

29. Sharma BR, Shah CN (2016) Nanoemulgel: A comprehensive review on recent advances in topical drug delivery. Pharma science monitor. An International Journal of Pharmaceutical Sciences 7: 346-355. 